\title{
Disadvantaged older jobseekers and the concept of bounded agency
}

\begin{abstract}
This article uses the concept of bounded agency to interpret the findings of a study that explored the training and job-seeking activities of a group of older adults. A qualitative, phenomenological approach was used to obtain personal and nuanced accounts of their experiences. A series of semi-structured interviews was conducted with eight adults aged 55 and older, who were low-skilled and unemployed. The findings identified that a range of interrelated barriers constrained their agency in those activities in two key areas. First, there was a disparity between their learning needs and preferences, and the delivery modes in their training programmes. Second, legacies from their personal histories contributed significantly to constraints in their current activities. The bounded agency concept explicated this range of barriers, as it incorporated institutional, societal and personal factors within the agency of individuals. A model of bounded agency was developed, that showed legacies from an individual's personal history can lie at the base of their disadvantaged state, and that provisions in their training programmes can address those legacies. The article concludes by suggesting that this model could form the basis of further research with other jobseekers from disadvantaged backgrounds.
\end{abstract}

Key words: bounded agency, disadvantaged, jobseekers, older, training

\section{Introduction}

This article discusses the findings, using the concept of bounded agency, of a study that explored the training and job-seeking experiences of a group of eight older adults. The adults were 55 years of age and older, low-skilled and unemployed, and were participating in training and job-seeking activities to increase their employability. Their participation in those activities was seen as an instance where a complex range of interrelating factors coalesced and created barriers that constrained their agency in relation to their ability to achieve their goals. As such, their experiences appeared to provide an apposite example of the concept of 'bounded agency', which is discussed further in this article.

The context of the study includes the current demographic trends of an ageing 
society, and the goals of Organisation for Economic Co-operation and Development (OECD) governments to increase the labour force participation rates of older adults (4564 years old) (van Nimwegen and van der Erf, 2010). Due to workplace changes and the fact that many older adults' workplace skills are outdated, some may need to 'upskill' (Daehlen \& Ure, 2009; O'Keefe, Crase, \& Dollery, 2007). The use of the concept of bounded agency has been shown to be a useful tool in explicating the interrelated barriers for this group. However, an existing model of bounded agency does not describe the circumstances of disadvantaged older adults sufficiently. Thus a new model is presented; this was developed to more accurately describe the particular sets of factors impacting on this group. It is suggested that this model could also be useful in describing barriers to training and job-seeking for others from disadvantaged backgrounds.

Based on the analysis of the data, the article suggests that the existing provisions are inadequate for those defined as disadvantaged in the contemporary labour market. Training programmes offered to this group did not address long-term legacies arising from their personal histories, nor did they respond to their specific learning and support needs. It is proposed that, for this group, barriers that arose during training programmes and the subsequent lack of translation into employment were a consequence of bounded agency.

\section{Demographic trends}

Current demographic trends, such as an ageing population and the retirement of skilled workers, are posing challenges to the economic stability of Australia and other OECD countries. This section outlines those challenges, highlights the economic and social impacts of a failure to address them and outlinesthe governmental strategy of increasing the labour force participation rate of older adults.

Australia and other OECD member countries are experiencing considerable demographic challenges, characterized by two phenomena. First, the population is ageing, as longevity increases and birth rates decline (Australian Bureau of Statistics [ABS], 2010; van Loo, 2011). Second, there is a decline in the labour force participation rate of older workers, which is coupled with the retirement of skilled workers (Australian Human Rights Commission [AHRC], 2009). This trend is claimed to be due 
to the rapid social, economic, and cultural changes that have occurred over the last century (Taylor, Jorgensen, \& Watson, 2010). So, while there are increasing numbers of older people living and working longer in those countries, there are still not enough people in the upper age bracket participating in paid employment to offset the economic imbalance brought about by these demographic trends (Deloitte Access Economics, 2012).

It is predicted that a continuation of these trends represents a threat to living standards in OECD countries (McLachlan, Gilfallan \& Gordon, 2013; Warren \& Oguzoglu, 2010). In Australia, these trends would have a negative effect on the national labour market and could cause a severe decline in the capacity to realise economic goals, and a projected slowing of gross domestic product growth (Deloitte Access Economics, 2012; Productivity Commission, 2013). One response to those challenges has been the decision to raise the age of eligibility for pension entitlements (Deloitte Access Economics, 2012; The Treasury, 2014).

Studies by Paul and Moser (2009), Ranzijn, Carson, Winefield, and Price (2006) and Winkelmann (2009) claim there are also those who could be psychologically and socially damaged by these trends. Those studies show a link between loss of employment and reduced well-being, and that unemployed people are more likely to suffer from depression and health problems, including psychological disengagement, and a lack of motivation. Thus, governments of Australia and other OECD countries have deemed that existing policies designed to sustain economic growth need to be aligned with those that incorporate all available labour reserves (OECD, 2006).

\section{Participation in training and employment}

A primary strategy to offset the impacts of those demographic challenges has been to increase the labour force participation rate of older adults (van Loo, 2011; van Nimwegen \& van der Erf, 2010). However, while that strategy is high on the policy agendas of most European countries (Cedefop, 2013), according to statistical data, in some countries the participation rate of this group of workers has been declining (Taylor et al., 2010; van Nimwegen \& van der Erf, 2010). This trend is often a combination of the attitudes and practices of employers (Billett, Dymock, Johnson, \& Martin, 2011; van Loo, 2011) and the skills obsolescence of employees (Mayhew, Elliott, \& Rijkers, 2008). 
It has also been suggested by Haveman (2010), that the Australian social security system is providing disincentives for older jobseekers securing, or remaining in, employment or training, as obtaining income support is too easy. This is seen as one reason why, in Australia, participation levels by older adults in accredited training programmes are low and are continuing to decline as these adults age (AHRC, 2009; Department of Employment, Education and Workplace Relations [DEEWR], 2008).

A key point is that while Australia and other OECD countries are advocating policy reforms to encourage larger numbers of older adults to return or remain for longer in the workforce, a range of factors and barriers impact negatively on their participation in both training and job-seeking activities. These include: (a) institutional barriers, such as welfare benefits and financial disincentives, such as superannuation systems and retirement arrangements; (b) societal sentiments, such as age discrimination, reflected in employer attitudes and practices; and (c) individual factors, such as health issues, and personal barriers, such as low self-esteem and a lack of selfconfidence (Dockery \& Ong, 2011; Headey, 2011; OECD, 2006; Temple, Adair, \& Hosseini-Chavoshi, 2011). Considering the economic and social consequences of not addressing the current demographic trends, there is an imperative to reduce the barriers that exist to limit the participation of older adults in both training and job-seeking activities (The Treasury, 2010).

\section{Exploring the experiences of disadvantaged older jobseekers}

The economic imperative to increase the labour force participation rate of older adults provided an impetus for this study, as it explored their experiences participating in training and job-seeking activities, with an aim to provide suggestions that could lead to meaningful roles for them within the contemporary workforce. Previous studies conducted from the perspective of older adults - that is, in their 'voice' - have been largely absent from the literature (Lundberg \& Marshallsay, 2007; Tikkanen, 2009). To address this gap in the research, the study utilized a qualitative, phenomenological approach to provide an in-depth exploration of the experiences of the participants, in relation to the concept of bounded agency. This section outlines and justifies the methodology, describes the participants, and discusses the theories utilised in both the investigation and analysis. 


\section{Methodology}

The study utilized a qualitative orientation because of its capacity to obtain a detailed understanding of an issue, to empower individuals to share their stories (Miles \& Huberman, 1994), as well as to minimize the power relationships that often exist between a researcher and the participants in a study (Merriam, 1998). A phenomenological approach was considered the most appropriate for this inquiry, because this approach can secure insightful, personal accounts (Creswell, 2007; Groenewald, 2004) and is suitable when the question has 'both social meaning and personal significance' (Moustakas, 1994, p. 103). Small representative sample sizes are recommended when adopting a phenomenological approach to a study (Creswell, 2007). Thus, in this study, eight participants were chosen to enable a nuanced understanding of their experiences and consistent with a phenomenological approach. Semi-structured interviews organized around a set of predetermined questions were selected as a method of data gathering, because it enabled a comprehensive exploration of the subjectivities of a small group of participants, as suggested to be appropriate by Creswell (2007) and Whiting (2008).

The data-gathering process involved a series of five one-on-one, face-to-face semi-structured interviews with the eight participants, over a five- to eight- month period, using pre-prepared interview protocols. The primary research question was: 'What are the experiences of disadvantaged older jobseekers participating in training and job-seeking activities to increase their employability?' Three secondary research questions sought to illuminate how the exercise of personal agency was constrained during the participants' training and job-seeking activities. These questions were: (1) 'How do these older job-seekers perceive institutional provisions and conditions as constraining their agency?' (2) 'How do these older job-seekers perceive societal expectations and sentiments as constraining their agency?' and (3) 'How do these older job-seekers perceive personal factors and barriers as constraining their agency?'

\section{The participants}

The participants were selected through purposive sampling, a procedure deemed appropriate when a study requires the selection of 'unique cases that are especially 
informative' (Neuman, 2006, p. 222), as was the case here. They consisted of eight adults - five females and three males - from a variety of backgrounds, who were undertaking a range of vocational qualifications to increase their employability. Despite their varied backgrounds, they all had in common three historical factors that appeared to pre-determine their disadvantaged status in the contemporary labour market. First, they had an education and training history that was shaped and limited by the societal expectations and historical events in the era during which they were of school age. Second, they had only attained a low skills base. Third, they had work histories that had been inconsistent, characterized by a pattern of part-time or casual work, and long periods of unemployment, often due to family responsibilities and obligations particularly for the women.

The participants were 55 years of age or over, low-skilled and under-employed or unemployed, and thus classified by the Australian government as 'disadvantaged older workers' (McLachlan et al., 2013). Due to their being under- or unemployed, it was deemed appropriate to term them 'jobseekers' rather than 'workers', as their unemployed status placed them at more of a disadvantage than would be faced by an older 'worker'. Although six of the participants were born and raised in country towns, at the time of the interviews, they all resided in an Australian capital city. All the names used are pseudonyms, chosen by the participants.

Theories utilized to explore the key issues

Theories relevant to personal responses to external factors and barriers, and the conceptual lenses that support those theories, were considered an important component in understanding the participants' learning and support needs. Theories proposed by Billett (1998) in relation to an individual's personal histories, or ontogenies, were considered, as well as how they related to occupational, social and personal identity, as theorized by Archer (2000), Bandura (2006), Stets and Burke (2000) and Taylor (1985). These theories were also seen to relate to those of Bandura (2006), in describing an individual's sense of self and self-efficacy, and were used to identify how participants were able to maintain their sense of self and identity under challenging conditions. From these theories, the investigation considered conceptions of life transitions and trajectories, advanced by George (1993), Lagenkamp (2011), Kroneman, Loeber, 
Hipwell, and Koot (2009) and Martens (2000), to explore the genesis of dispositions and intentionalities of the participants. These theories assisted in explaining how events or transitions experienced earlier in life - such as childhood traumas - may be linked to subsequent life course patterns.

Theories of agency were of most relevance, particularly considerations by Billett and Pavlova (2005), who suggest that the role of agentic action includes its relationship with individuals' subjectivities, or their sense of self. This viewpoint is aligned with the work of Bandura (2006) and Archer (2000), who hold that most human functioning is socially situated, and that agency always operates within and through a social structure. In this way, Billett (2006) suggests that there is a relational interdependence between the socially constructed individual and the social world. Theories of epistemological agency - most notably from Billett and Smith (2006) and Billett, Smith, and Barker (2005) were used to provide an understanding of individual learning needs and to explore how individuals attempt to negotiate barriers to participation in training activities.

Due to the fact that the group's participation in training had been instigated and, in some cases, was funded by the government, their experiences of disincentives and discouragement from within Australia's social security system, or 'welfare state', appeared to be a pertinent issue to investigate. For example, Zoellner (2012) suggests that structural conditions are often perceived as a form of 'biopower' - that is, a means whereby governments can exercise control over the population. Also, it has been claimed by Jenkins (2008) that the use of derogative terminology to categorize particular socially disadvantaged groups can produce inequalities of power and resources. These theories formed the basis of both the investigation and the interview questions. However, it was thought that one governing concept should be considered, that provided a link between all the theories.

\section{The concept of bounded agency}

The concept of bounded agency was thought to provide an overarching understanding of the above theories. Shanahan and Hood (2000) suggest that when the outcome of the interplay between institutional and personal factors constrains the agentic action of an individual, it can result in a state termed 'bounded agency'. Contemporary theorists have drawn on the work of French sociologist and philosopher Bourdieu (1990), whose 
theory of 'habitus' and field, or social context, is relevant here, to explain the concept. Authors such as Evans (2002, 2007), Boeren, Holford, Nicaise, and Baert (2012), and Rubenson and Desjardins (2009, 2013) used the concept of bounded agency to investigate the barriers to adult participation in post-compulsory education, in particular concerning the relationship between individual agency and the structural conditions prevalent in society.

The findings of Evans (2007) support the thesis that highly structured employment and training environments are associated in people's minds with the idea of reduced scope for individual, proactive effort. Similar conclusions can be drawn from the studies of Boeren and colleagues (2012) which found that participation is shaped by a bounded agency between the individual and education policy and practice, and that putting pressure on individuals to learn through social control is not effective in stimulating motivation and engagement. Findings from Rubenson and Desjardins' (2009) study suggest that the structures and conditions of an individual's 'habitus' can be seen as a system of dispositions, both directly and indirectly affected by the 'welfare state regime', which governs how a person acts, thinks, and orients themselves in the social world. They claim that 'regime' is a clear example of a system that contains within it a range of factors that can be regarded as institutional and societal, and those that can be seen as personal, or individual, which can 'bound' individual agency. Evans (2007, p. 93) described bounded agency as 'socially situated agency influenced but not determined by environments and emphasizing internalized frames of reference as well as external actions'.

To provide a conceptualisation of the concept of bounded agency, Rubenson and Desjardins (2009, p. 195) designed a 'Bounded Agency Model', which, on the one side, shows how broad structural conditions and targeted policy measures directly affect the extent and impact of institutional and situational, or job- and family-related, barriers, while on the other side, those factors that are individual relate to disposition, or dispositional barriers, such as belief in one's capabilities and 'consciousness', a term used by Bourdieu (1990). The model illustrates how individual agency is limited by a combination of dispositional barriers and those from structures and conditions of the 'welfare state regime'.

From the above discussion, it can be seen that the concept of bounded agency 
incorporates components that correspond to the three broad categories of factors claimed by government agents to produce barriers to training for older adults: institutional, societal, and personal (OECD, 2006; Temple et al., 2011). In this way, the concept aligned well with the purposes of this study, due to the apparent link between the structural conditions of the welfare state, barriers to participation in training, and the socially embedded nature of certain psychological concepts. The investigation of these interrelated barriers provided a landscape where the concept of bounded agency could be deployed as a governing framework.

\section{The experiences of disadvantaged older jobseekers}

As the study concerned the experiences of disadvantaged older adults, it was considered essential to ascertain their social history and pre-mediate learning experiences, in order to understand the genesis of their current circumstances. Thus, the findings consisted of a nuanced account of the participants' experiences concerning two phases of their lives: family background and transitions to adult roles, including training and employment history, and the training and job-seeking activities in their current circumstances.

\section{Family background and training and employment history}

It was found that the participants' early experiences, events and environments impacted on the decisions that they made regarding education and training beyond their compulsory school years. All eight participants were from low socio-economic backgrounds, which, they claimed, limited their options and impacted on their psychology. Those environments notably included the societal expectations of their childhoods and youth. Seven participants wanted to attend post-compulsory education, but only two achieved their goal. However, of those two, one participant - Tamara, was the child of Russian immigrants who had been traumatized by events in World War II. She reported that her parents did little to encourage her artistic talents, and that her motivation to pursue study and employment was impacted by those family traumas, noting that 'I had nothing to aspire to, I aspired to nothing.' Four participants had suffered the loss of a parent in childhood and one of them - Kelvin, stated: 'I remember hardship, deprivation.'

In their transitions to adult roles, it was found that the participants' family 
responsibilities and obligations took precedence over them gaining qualifications and other formal training. For example, Linda reported that because of the low expectations for women in that era, she was married with a baby on the way by the age of 18 . Over the next 15 years she reported that she had five more children but, because the family's finances were limited, both she and her husband had to work. Due to the lack of time and support for tertiary education, Linda also reported that she could only gain casual, low-skilled employment. Similarly, Ellie-May had four children, and also needed to supplement the family income. Yet, with her family responsibilities and no post-school education, Ellie-May reported that she had only applied for jobs that required her to work after-hours, such as casual work, and those kinds of employment that required little or no training. However, these expectations did not only affect the female participants. Noah, who identified as an Indigenous Australian, reported that there was no support for tertiary training from within his family, and no exemplars within his community. He claimed that, after his father died, he was expected to leave school midway through Year 9 to look after his mother and sister. He reported that he spent 20 years as their principal caregiver. Noah claimed that in this way, his community 'stifled' him. He said 'I basically raised myself.'

The development and expression of the participants' dispositions and epistemologies varied across the sample, and contributed to differences in their abilities to exercise personal agency to overcome their limitations. For instance, Linda admitted that she had an 'aggressive, angry' nature, but that this temperament generated in her a desire to improve her lifestyle. She exercised her agency by taking advantage of the opportunity to gain a tertiary education as soon as fees were waived. However, EllieMay conceded that her sense of self and disposition has been strongly influenced by both her mother's death and her grandmother's social expectations of the role of a woman, and, for this reason, she endured 32 years of marital abuse.

These findings were analysed in relation to literature suggesting a link between events or transitions experienced earlier in life, especially childhood traumas - such as the loss of a parent, or physical abuse - and how they can affect subsequent life-course patterns (George, 1993; Kroneman et al., 2009; Lagenkamp, 2011; Martens, 2000). These findings indicated that, although each participant exercised their agency to a greater or lesser degree, factors in their personal histories often constrained their efforts 
to participate in training or education, and to pursue work that was worthwhile and personally satisfying.

\section{Training and job-seeking activities in their current circumstances}

In relation to their training and job-seeking activities, there were five key findings: three that related to external factors or barriers, one that related to personal barriers, and one that offered suggestions for improvement, from the participants. First, there were frequent reports of discrimination in employer attitudes and practices, particularly by the female participants; these were perceived as limiting their employment prospects, a finding aligned with other literature regarding ageism (AHRC, 2009; Tikkanen, 2009). Illustrative of their experiences, Ellie-May commented, 'I'll go into an interview and the minute they look at you, you know. They say "You're not what we're looking for”. Age goes against you.' Similarly, Linda, who was 62 years of age claimed, 'They don't say, because legally they can't, but all they've got to say is that someone else they interviewed was more suitable. But I've known it's because of my age.' Conversely, Kelvin observed, 'As a white male, I'm probably subject to less discrimination than most people in society.'

Second, a disparity emerged between the participants' preferred ways of learning and the delivery modes in their training programmes. This was due to their reported low levels of computer literacy, and was reported as constraining their ability to complete the online assessment tasks and as contributing to a lack of confidence in their learning ability. For example, Ellie-May stated, 'I'm finding it very hard. If you're computer literate, you can breeze through most of these courses. If you're like me, and most people in my age group, then, Nah!' Similarly, Linda admitted that she felt frustrated by her lack of computer literacy, saying she was 'a technophobe.' But she reported that she believed she could achieve her goals, if she could have assistance improving her computer literacy, stating, 'That's why I say I'm like a caged lion.' Noah reported that he had a very low level of computer skills and that this deficiency directly impacted on his confidence and ability to study. From this finding, the participants' lack of computer literacy appeared to represent a significant barrier to increasing their employability.

Third, difficulties in interpersonal communications between the participants and officers in the social security agencies of the Australian welfare system (Centrelink) 
were identified. Four participants reported variously that they were 'frustrated' and 'angry' in their personal dealings with staff. For instance, Corinne commented, 'I think Centrelink is just this wall that the government puts up, to stop people getting to them, to the people who should be doing something about it.' Similarly Dan suggested that, for his cohort, the system was 'cutting them off at the knees, putting another set of hurdles in the way.' Under the 'Newstart Allowance Scheme' (Department of Human Services, 2014), recipients of unemployment benefits are obligated to undertake governmentfunded training with the presumption that it will increase their employability. The five participants who received the Newstart benefits reported their belief that training would not necessarily translate into employment. Nevetheless, such training was a requirement of receiving these benefits. For example, Linda, stated: 'I've worked all my life, and there is nothing at the end. I'm tired of the struggle.' Similarly, when asked whether she thought her training would lead to employment, Suzanne asked rhetorically, 'Seriously? No! What's the point of getting a qualification if there are no jobs at the end of it?' These sentiments illustrate how external pressures to keep working proved difficult for some of the participants. At the end of the study, after approximately eight months, none of the participants' training activities had resulted in full-time employment and, in fact, several participants had become unemployed.

Fourth, it was found that these external factors created dispositional barriers for the participants. For example, Linda stated, 'You get into a spiral down-turn, you become depressed.' Similarly, Ellie-May commented, 'There are days when I could just stay curled up in bed.' Suzanne reported that her lack of confidence came from not being valued, stating that she felt a 'loss of self-worth. That's what I feel. We're not worth the time of day.' Two participants, Noah and Tamara, were termed 'Very LongTerm Unemployed' (Temple et al., 2011), having being out of work for four and five years respectively. Regarding his long-term employment, Noah stated, 'Oh, ah, I was insecure, I didn't have the confidence to do anything.' When Tamara was asked about her job-seeking activities since the last interview, she replied, 'But I'm terrified to look for a job; haven't done a thing! I just feel so inadequate'. Dan had been working continuously in the automotive industry for 40 years, had studied to become a trainer, but had been retrenched due to a downturn in his industry from a change in governmental policy. He commented that, 'My sense of self and self-worth has taken a 
bit of a battering since I've been unemployed.' His dispositional barriers lead him to seek assistance from a psychologist who diagnosed him with post-traumatic stress disorder.

Fifth, when the participants were asked for suggestions to improve their employment opportunities, several expressed strong opinions. For instance, Ellie-May said that Centrelink support could be improved and that 'The only thing is to have somebody in those age groups that understands, in those departments.' Similarly, Corinne stated that 'I think they [Centrelink] should be looking at their programming, and look at the differences in the age groups, so that Centrelink treats you differently if you're in that age group.' When asked for suggestions regarding improving their training activities, many participants suggested more targeted training. For example, Noah broadly suggested that 'They [older adults] should get training, and it should be funded, yes. But we are the mediators of society, and if we don't get nurtured, how can we nurture anyone else? Whether you're skilled or semi-skilled, you know, life skills, there should be something around that.' David's suggestion was more specific, in that 'It goes back to the need to tailor the learning to the individual's learning style.' Similarly,

Kelvin stated 'I think training has to be based on the individual, rather than a curriculum, a pro-forma that we are meant to fit into.' These sentiments suggest that with appropriate support, these participants believed they may have been able to exercise their agency to achieve more positive employment outcomes.

The participants in the study were all undertaking training activities to increase their employability. Yet the data showed that none of the participants was fully employed before, during or at the end of the series of interviews. These findings indicate that the participants experienced barriers to their training and job-seeking activities, albeit in person-dependent ways. Those barriers were not isolated, but interrelated.

\section{The bounded agency of a group of disadvantaged older jobseekers}

The participants' responses indicated that their agency was bound by a combination of both external and personal barriers. They attributed external barriers to creating or exacerbating personal or dispositional barriers for them. Indeed, the data provided many examples of the interrelatedness of barriers. For instance, Dan reported that he could not 
locate a suitable workplace in which to practise his assessments tasks, which he claimed contributed to his depression. In order for Dan to improve his mental health, he suspended his studies, and focussed on gaining employment. Linda reported her belief that her employment prospects were limited by her ill-health and ageism from prospective employers. The participants' employment outcomes suggest that they did not necessarily benefit from the provisions supplied by government agents or training providers in ways that manifestly improved their employment status. Rather, their responses indicated that participants' perceptions of government provisions and experiences in training programmes lead to dispositional barriers. Based on similar conclusions in their study, Rubenson and Desjardins (2009) suggest that both the type and severity of barriers to participation, as well as the capabilities of individuals to overcome them, are affected by the nature of what is provided by 'welfare state regimes'. This suggestion certainly applied to this group.

Although possessing individual dispositions and identities, the participants in this study had in common low levels of skills, due to low levels of education and training, and an inconsistent work history. It was found that, despite individual ways of exercising their agency in their youth and young adulthood, the participants reported being overwhelmed by the effects of a combination of those historical factors, and the barriers faced in their current circumstances. Indeed, the data are aligned with social cognitive theory, in that a low sense of self lowers belief in personal efficacy (Bandura, 2006), and severely limits an individual's ability to exercise their agency, or to 'withstand constant threats to their sense of self' (Billett \& Pavlova, 2005, p. 4). For some of the participants, faced with an uncertain future due to being unemployed, lowskilled and over the age of 55, those 'threats' to their sense of self became critical.

Six of the participants who related that they suffered feelings of depression and a loss of a sense of self, had reportedly experienced abuse, or the death or absence of a parent, or had a strained relationship with a parent in their childhood - a finding aligned with the literature in this field (George, 1993; Kroneman et al., 2009; Martens, 2000). For Noah and Tamara, their current work prospects were compounded by issues surrounding their ethnic and cultural backgrounds, a factor also found in other studies (Lagenkamp, 2011). Thus it is suggested that legacies from the participants' personal histories combined with issues in their current circumstances to constrain their agentic 
action.

From these illustrations, and the data, the concept of bounded agency was found to be useful in describing the interrelationship of the barriers that impacted on this group. However, although it is accepted that bounded agency has been 'shaped by the experiences of the past' (Evans, 2002, p. 262), previous studies using this concept do not fully accommodate the legacies of individuals' life histories. The dispositions of adults 55 years and older are long term and shaped by values and structures from a lifetime of experiences. The model conceived by Rubenson and Desjardins (2009) was found to have limitations in describing the particular sets of interrelated barriers facing disadvantaged older jobseekers, such as those in this study. Therefore, a new model was developed, as shown in Figure 1. It has a four-level structure: the lowest or first level denotes the 'historical background' of the participants, including factors that defined them as 'disadvantaged older jobseekers'; the second level denotes their 'current circumstances' (factors and barriers); the third level has two aspects of 'individual agency': bounded agency on the left-hand side, and agentic action on the right-hand side; the fourth level, at the apex, denotes 'employment status', showing two possible outcomes for employment: on the left-hand side, the outcome is under- or unemployment, and on the right-hand side, the outcome is employment.

Place Figure 1 here

Figure 1. A Model of Bounded Agency

In more detail, the first level shows the 'historical background' as being at the base of the model, indicating its role as defining the participants as disadvantaged older jobseekers. Notable factors in their historical background included low levels of education, a low skills base, and an inconsistent employment history, including long periods of unemployment. The second level, 'current circumstances', includes factors and barriers that were external to the participants, and factors and barriers that were personal. External factors included affordances from government policies, structural conditions, training provisions, and societal sentiments - some of which were perceived by the participants as barriers. Personal factors included capabilities, disposition, identity, and sense of self, some of which became dispositional barriers for the participants. It was 
during their participation in training that perceived barriers from their historical background and current circumstances coalesced, forming an interrelationship between a range of barriers.

The third level shows two aspects of individual agency: bounded agency and agentic action. The data suggest that certain experiences in the participants' early years enabled them to exercise their agency in some ways. Yet, the data from their current circumstances - that is, while participating in training and job-seeking activities indicated that a range of barriers constrained the exercise of their agency. The participants reportedly suffered from low self-esteem and low self-confidence, and their responses reflected that they were often unable to overcome the combination of historical, dispositional, structural and societal barriers. That is, although there was acknowledgement from the participants that they had some degree of agency, their responses indicated that it was not sufficient to overcome the range of barriers they faced. Thus it is posited that they had bounded agency, a negative outcome which limited their employment opportunities.

The findings show a relational interdependence between personal agency and the provisions offered by external agents, while participating in training activities. This interdependence also suggests that, unlike those conditions described by the participants, a supportive environment could enable agentic action for individuals. Conversely, this interdependence suggests that structures from institutions negatively impacted upon, or created dispositional barriers for, the participants, and constrained their agentic action.

From those two aspects of agency, the fourth level at the apex of this model shows that two possible employment outcomes were available to this group. The employment status resulting from bounded agency reflects the outcomes for the group by suggesting that for those with low self-esteem and low self-efficacy, there was a possibility of their outcome being under-employment or unemployment. Conversely, the fourth level also suggests that if the participants had been supported in exercising their agency, there could have been a possible employment outcome for them.

The model illustrates how the participants' personal histories were at the base, or were generative, of their disadvantage in the labour market, and that legacies from those histories were compounded by inappropriate and unsupportive provisions in their 
training and job-seeking activities, shown in the second level. Here the model identifies a range of institutional and societal barriers that compounded personal barriers and constrained agentic action, illustrated in the third level. For these participants, their bounded agency resulted in negative employment outcomes. The levels in the model each contain a range of factors, which influences the level above, in a unidirectional way, determined by the passage of time. The model reinforces the claim by Billett (2006) that the exercise of agency is dependent on an interrelated range of influencing factors. Their continued under-employed or unemployed status shows the possible negative outcomes of their bounded agency. This model, although representative of this particular group, may inform an understanding of other disadvantaged groups.

\section{Implications for policy, practice and theory}

Given the interrelated range of barriers to the participation in training and job-seeking for this group, it is suggested that a range of measures need to be introduced to mitigate those barriers. This section presents implications for policy, practice and theory.

The data, together with conclusions from authors such as Rubenson and Desjardins (2009) and Evans (2007), suggest that public policy has a role to play in mitigating both structurally and individually based barriers to participation. Given the predicted negative economic and social impacts on both individuals and the nation, it would seem that supporting this cohort to participate in training and job-seeking activities should be a basic policy imperative. In addition, if financial disincentives for this cohort from within the welfare system are influencing their motivation to participate, but adversely affecting the economy, then they need to be examined. Therefore, it is suggested that reforming our welfare system should become a policy priority (Dockery \& Ong, 2011). One measure of reform in Australia and other OECD countries, is the plan to raise the eligibility age for pension entitlements (Deloitte Access Economics, 2012). Indeed, the Australian Government has recently suggested that, between the years 2017 and 2023, they raise the eligibility age for pension entitlements to 70 years (The Treasury, 2014).

The disparity that emerged between the participants' preferred ways of learning and the delivery modes in their training programmes suggests a need for targeted training for this cohort - disadvantaged older jobseekers. It is suggested here that this 
disparity not only created barriers for this group, but could, if extended to the cohort, create a disincentive to participate in both training and employment activities.

The unsatisfactory employment outcomes for this group reflects an area where adequate, sufficient and appropriate support can be provided to facilitate a positive outcome in terms of employment status for similarly situated older adults. This is reflected at the level of the second level in the new model. This support does not necessarily have to be vocational training, but could include other forms of education and training, or simply, as one participant suggested, 'life skills'. Taking into account age discrimination and job availability, it is suggested that there is a possibility of a positive employment outcome for those who are supported in exercising their agency, in ways that empower them, by increasing their self-esteem and thereby also increasing their self-efficacy. Indeed, it is possible that targeted support for those who are disadvantaged in the labour market, may elevate their self-esteem and self-efficacy, and thus contribute to their ability to exercise their agency to achieve improved employment outcomes.

Further research needs to be conducted into the barriers facing not simply older, but disadvantaged older jobseekers using the bounded agency concept. A qualitative study, such as the one discussed here, would give a voice to those who are marginalised in both society and the labour market. That research would hopefully provide strategies to mitigate barriers to their participation in training and job-seeking activities, and thereby, improve their employment prospects. It is also suggested that directions could be provided for those strategies by the model presented here. Although this model reflects the situation and outcomes for this group's participation in training and jobseeking activities, it could be used to describe similar situations and outcomes for others - younger or older - from disadvantaged backgrounds. 


\section{References}

Archer, M. S. (2000). Being human: The problem of agency. Cambridge, England: Cambridge University Press.

Australian Bureau of Statistics (ABS). (2010). Australian social trends, September 2010: Older people and the labour market. (Cat. No. 4102.0). Retrieved from http://www.abs.gov.au/AUSSTATS/abs@.nsf/0/97999E77DB6843A1CA2577F80 010DD40?opendocument

Australian Human Rights Commission (AHRC). (2009). Experience works: Report highlights our hidden age-discrimination problem. Retrieved from https://www.humanrights.gov.au/news/media-releases/2009-media-releaseexperience-works-report-highlights-our-hidden-age.

Bandura, A. (2006). Toward a psychology of human agency. Perspectives on Psychological Science, 1(2), 164-180.

Billett, S. R. (1998). Ontogeny and participation in communities of practice: A sociocognitive view of adult development. Studies in the Education of Adults, 30(1), 21-34.

Billett, S. R. (2006). Relational interdependence between social and individual agency in work and working life. Mind, Culture and Activity, 13(1), 53-69.

Billett, S. R. (2011). Older workers, employability and tertiary education and training. In T. Griffin \& F. Beddie (Eds.), Older workers: Research readings (pp. 97-109). Adelaide, Australia: National Centre for Vocational Education Research.

Billett, S. R., Dymock, D., Johnson, G., \& Martin, G. (2011). Last resort employees: Older workers' perceptions of workplace discrimination. Human Resource Development International, 14(4), 375-389.

Billett S. R., \& Pavlova, M. (2005). Learning through working life: Self and individuals' agentic action. International Journal of Lifelong Education, 24(3), 195-217.

Billett, S. R., \& Smith, R. (2006). Personal agency and epistemology at work. In S. Billett, T. Fenwick, \& M. Somerville (Eds.), Work, subjectivity and learning (pp. 141-156). Dordrecht, Netherlands: Springer.

Billett, S. R., Smith, R., \& Barker, M. (2005). Understanding work, learning and the remaking of cultural practices. Studies in Continuing Education, 27(3), 219-237.

Boeren, E., Holford, J., Nicaise, I., \& Baert, H. (2012). Why do adults learn? 
Developing a motivational typology across 12 European countries. Globalisation, Societies and Education, 10(2), 247-269.

Bourdieu, P. (1990). The logic of practice. Cambridge, England: Polity Press.

Cedefop. (2013). Empowering vulnerable adults to tackle labour market challenges:

Findings from study visits 2010/11 and 2011/12 and policy implications.

Luxembourg: Office for Official Publications of the European Communities.

Creswell, J. W. (2007). Qualitative inquiry \& research design: Choosing among five approaches ( $2^{\text {nd }}$ ed.). Thousand Oaks, CA: Sage.

Dæhlen, M., \& Ure, O. (2009). Low skilled adults in formal continuing education: Does their motivation differ from other learners? International Journal of Lifelong Education, 28(5), 661-674.

Deloitte Access Economics. (2012). Increasing participation among older workers: The grey army advances. Canberra, Australia: Author.

Department of Employment, Education and Workplace Relations. (2008). Australian vocational, education and training statistics: Employer use and views of the VET system: 2007 summary. Adelaide, Australia: National Centre for Vocational Education Research.

Department of Human Services. (2014). Payments for job seekers. Retrieved from http://www.humanservices.gov.au/customer/subjects/payments-for-job-seekers

Dockery, M. \& Ong, R. (2011). Measuring work disincentives: Taxes, benefits and the transition into employment. Australian Journal of Labour Economics, 14(3), 265288.

Evans, K. (2002). Taking control of their lives? Agency in young adult transitions in England and the new Germany. Journal of Youth Studies, 5(3), 245-269.

Evans, K. (2007). Concepts of bounded agency in education, work and the personal lives of young adults. International Journal of Psychology, 42(2), 85-93.

George, L. K. (1993). Sociological perspectives on life transitions. Annual Review of Sociology, 19, 353-373.

Groenewald, T. (2004). A phenomenological research design illustrated. International Journal of Qualitative Methods, 3(1), 1-26.

Haveman, R. (2010). Inequality, poverty and social mobility - What should happen after the recession [Newsletter]. Brisbane, Australia: QUT Business School. 
Headey, B. (2011). Economics of population ageing: Australia may not have a labour supply problem, but recent superannuation reforms have not helped. In T. Griffin \& F. Beddie (Eds.), Older workers: Research readings (pp. 67-80). Adelaide, Australia: National Centre for Vocational Education Research.

Jenkins, R. (2008). Social identity ( $3^{\text {rd }}$ ed.). New York, NY: Routledge.

Kroneman, L. M., Loeber, R., Hipwell, P. E., \& Koot, H. M. (2009). Girls' disruptive behavior and its relationship to family functioning. Journal of Child and Family Studies, 18(3), 259-273.

Lagenkamp, A. (2011). Effects of educational transitions on students' academic trajectory: A life course perspective. Sociological Perspectives, 54(4), 497-520.

Lundberg, D., \& Marshallsay, Z. (2007). Older workers' perspectives on training and retention of older workers. Adelaide, Australia: National Centre for Vocational Education Research.

McLachlan, R., Gilfillan, G., \& Gordon, J. (2013). Deep and persistent disadvantage in Australia: Productivity Commission staff working paper. Canberra, Australia: Productivity Commission.

Martens, W. H. J. (2000). Antisocial and psychopathic personality disorders: Causes, course and remission - A review article. International Journal of Offender Therapy and Comparative Criminology, 44, 406-430.

Mayhew, K., Elliott, M., \& Rijkers, B. (2008). Upskilling older workers. Ageing Horizons, 8, 13-21.

Merriam, S. B. (1998). Qualitative research and case-study applications in education. San Francisco: Jossey Bass.

Miles, M. B., \& Huberman, A. M. (1994). Qualitative data analysis ( $2^{\text {nd }}$ ed.). Thousand Oaks, CA: Sage.

Moustakas, C. A. (1994). Phenomenological research methods. Thousand Oaks, CA: Sage.

Neuman, W. L. (2006). Social research methods: Qualitative and quantitative approaches (6 $6^{\text {th }}$ ed.). Boston, MA: Pearson Education, Inc.

O'Keefe, S., Crase, L., \& Dollery, B. (2007). Does the reality of workplace training match the theory? An analysis of public sector employees' training decisions. International Journal of Training Research, 5(2), 41-54. 
Organisation for Economic Co-operation and Development (OECD). (2006). Live longer, work longer: A synthesis report. Paris, France: OECD.

Organisation for Economic Co-operation and Development. (2010). Trends shaping education 2010. Paris, France: OECD.

Paul, K. I., \& Moser, K. (2009). Unemployment impairs mental health: Meta-analyses. Journal of Vocational Behavior, 74(3), 264-282.

Productivity Commission. (2013). An ageing Australia: Preparing for the future: Productivity Commission Research Paper Overview. Canberra, Australia: Author. Ranzijn, R., Carson, E., Winefield, A. H., \& Price, D. (2006). On the scrap-heap at 45: The human impact of mature-aged unemployment. Journal of Occupational and Organisational Psychology, 79(3), 467-479.

Rubenson K., \& Desjardins, R. (2009). The impact of welfare state regimes on barriers to participation in adult education: A bounded agency model. Adult Education Quarterly, 59(3), 187-207.

Rubenson, K., \& Desjardins, R. (2013). Participation patterns in adult education: The role of institutions and public policy frameworks in resolving coordination problems. European Journal of Education, 48(2), 262-280.

Shanahan M. J., \& Hood, K. E. (2000). Adolescents in changing social structures: Bounded agency in life course perspective. In L. J. Crockett \& R. K. Silbereisen (Eds), Negotiating adolescence in times of social change (pp. 123-134).

Cambridge, England: Cambridge University Press.

Stets, J. E., \& Burke, P. J. (2000). Identity theory and social identity theory. Social Psychology Quarterly, 63(3), 224-247.

Taylor, C. (1985). Human agency and language: Philosophical papers 1. Cambridge, England: Cambridge University Press.

Taylor, P., Jorgensen, B., \& Watson, E. (2010). Population ageing in a globalising labour market: Implications for older workers. China Journal of Social Work, 3(2-3), 259-272.

Temple J., Adair, T., \& Hosseini-Chavoshi, M. 2011. Ageing and the barriers to matureage labour force participation in Australia. Canberra, Australia: Department of Education, Employment and Workplace Relations.

Tikkanen, T. (2009). The learning society as a greying society: Perspectives for older 
workers and lifelong learning. In Cedefop (Ed.) Modernising vocational education and training: $4^{\text {th }}$ report on vocational training research: Background report: Volume 2 (pp. 195-238). Luxembourg, Luxembourg: Cedefop.

The Treasury. (2010). Australia to 2050: Future challenges - the 2010 intergenerational report. Canberra, Australia: Attorney-General's Department.

The Treasury. (2014). The 2014 - 15 budget. Media release. Retrieved from http://jbh.ministers.treasury.gov.au/media-release/021-2014/

Van Loo, J. (2011). Making the most of mature minds: Issues, trends and challenges in making active ageing a reality. In T. Griffin \& F. Beddie (Eds.), Older workers: Research readings (pp. 13-20). Adelaide, Australia: National Centre for Vocational Education Research.

Van Nimwegen, N., \& van der Erf, R. (2010). Europe at the crossroads: Demographic challenges and international migration. Journal of Ethnic and Migration Studies, 36(9), 1359-1379.

Warren, D., \& Oguzoglu, U. (2010). Retirement in Australia: A closer look at the financial incentives. Australian Economic Review, 43(4), 357-375.

Whiting, L. S. (2008). Semi-structured interviews: Guidance for novice researchers. Nursing Standard, 22(23), 35-40.

Winkelmann, R. (2009). Unemployment, social capital, and subjective well-being. Journal of Happiness Studies, 10(4), 421-430.

Zoellner D. (2012). Dualism and vocational education and training: Creating the people who require training. International Journal of Training Research, 10(2), 79-93. 
Level 4

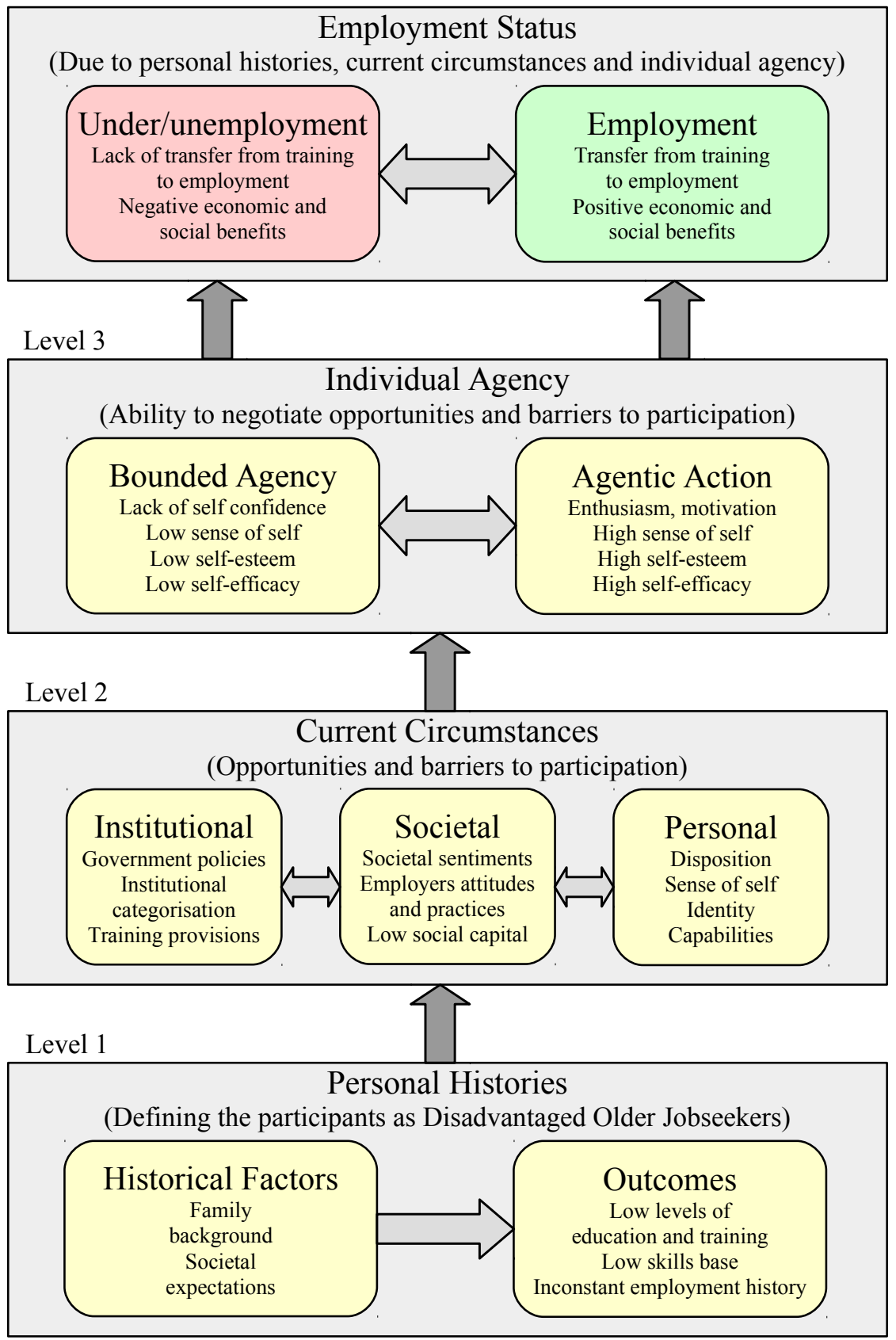

